\title{
Technological solutions for contributory citizen science: experiences from citizenMorph
}

\author{
Sabine Hennig ${ }^{1}$ \\ Interfaculty Department of Geoinformatics - Z_GIS, Paris Lodron University Salzburg \\ Schillerstr. 30, 5020 Salzburg, Austria \\ E-mail: sabine.hennig@sbg.ac.at \\ Lorena Abad \\ Interfaculty Department of Geoinformatics - Z_GIS, Paris Lodron University Salzburg \\ Schillerstr. 30, 5020 Salzburg, Austria \\ E-mail: Iorenacristina.abadcrespoesbg.ac.at

\section{Daniel Hölbling} \\ Interfaculty Department of Geoinformatics - Z_GIS, Paris Lodron University Salzburg \\ Schillerstr. 30, 5020 Salzburg, Austria \\ E-mail: daniel.hoelblinglasbg.ac.at
}

\begin{abstract}
Many citizen science projects invite people to contribute data. To fully exploit the existing potential, above all, the technological solutions must be in line with requirements coming from the citizens. This is particularly true for citizen science projects with a focus on fields such as geomorphology and landscape dynamics, which have so far received less attention and interest from the public. These fields often have difficulty to convince and engage citizens to contribute extensive, high-quality data to the topic under investigation. The question now is how to learn about citizens' requirements? What are these requirements? What do these solutions look like when implemented? This is discussed based on experiences from the citizenMorph project, which aims at developing technological solutions allowing citizens to contribute information on geomorphological phenomena (landforms). The results show that technological solutions encompass specific components, features, and approaches.
\end{abstract}

5th Austrian Citizen Science Conference 2019 (ACSC2019)

26-28, June 2019

Obergurgl, Austria

\footnotetext{
${ }^{1}$ Speaker

(C) Copyright owned by the author(s) under the terms of the Creative Commons 


\section{Introduction and Research Questions}

Citizen science describes the involvement of citizens, their knowledge, and their commitment to scientific processes. Different orientations to the basic idea of citizen science exist. The approach where citizens' can actively contribute data (contributory citizen science) is one [1]. While (contributory) citizen science has shown promising results in fields such as ecology, biology, or astronomy [2-4], less attention has been given to geomorphology and landform dynamics. There are only a few efforts to encourage citizen engagement on these topics [e.g., 5-6]. A reason is that the field of geomorphology generally faces problems to engage citizens since it is not an easily comprehensible topic that is often considered "boring" [7]. To arouse citizens' interest in geomorphology and landform dynamics, and to motivate them to contribute extensive, high-quality data, technological solutions must be created based on the requirements of the scientist but - even more important - of the citizens. The questions are how to learn about citizens' requirements? What are these requirements? What do these solutions look like when implemented? The citizenMorph project (Figure 1) addresses these questions.

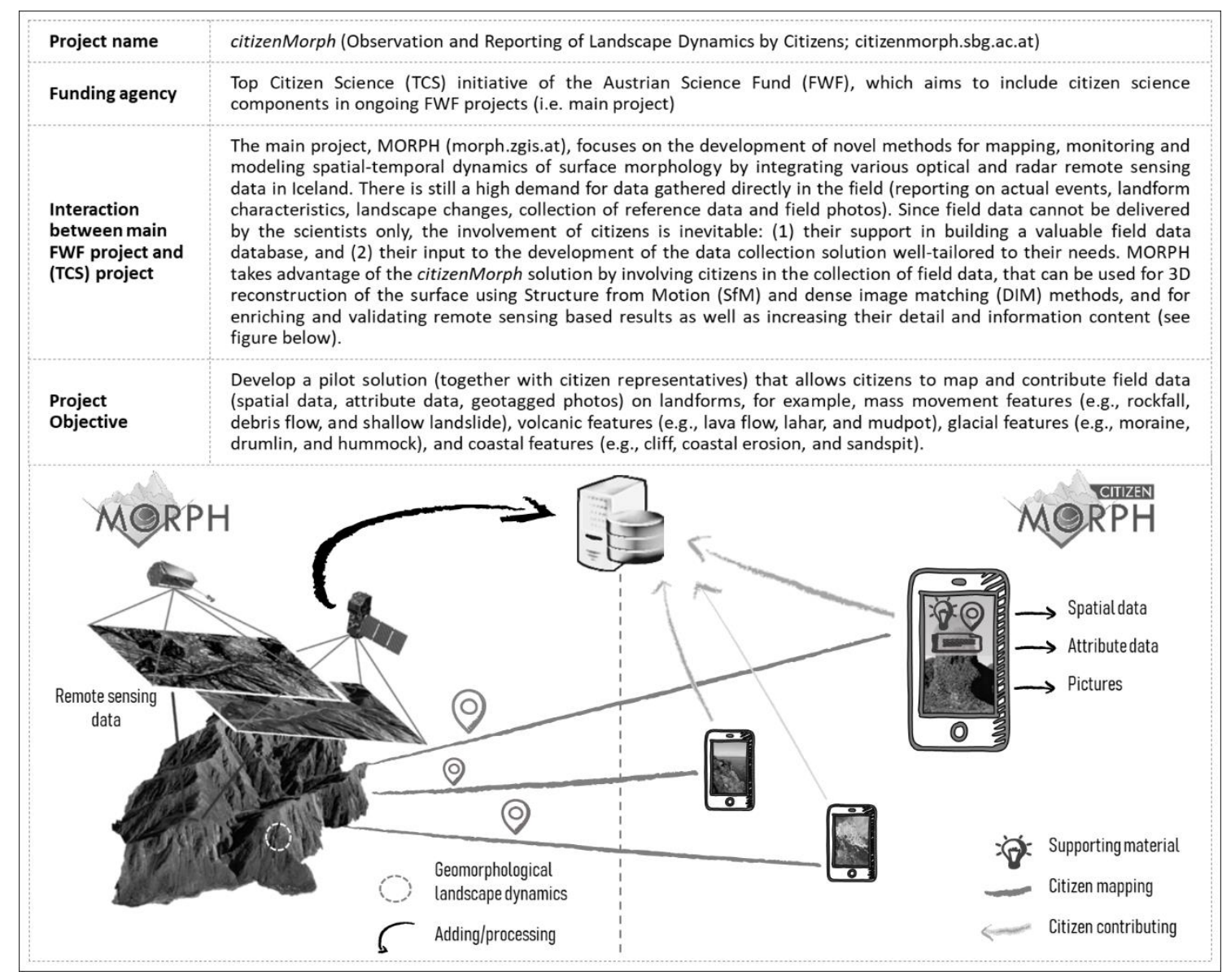

Figure 1: The citizenMorph project. 


\section{Workflow, Techniques, and Tools}

For the development of the citizenMorph technological solution (tailored to citizens' needs), different approaches and methods were used (Figure 2). The participatory design approach provided the general concept behind the development process. Participatory design refers to the direct and active involvement of target group representatives in development activities like requirements specification, design, implementation and testing, and in some cases, in decision-making [8]. Using this approach supports the development of solutions that provide better usability, increase the acceptance of the product in use, and ensure that the final solution meets the demands of the target group [9-10]. Besides, the prototyping process model was used: requirements were iteratively specified, and prototypes were iteratively created and discussed. Based on this, the final solution was designed and implemented (Figure 2).

Prototyping Process Model

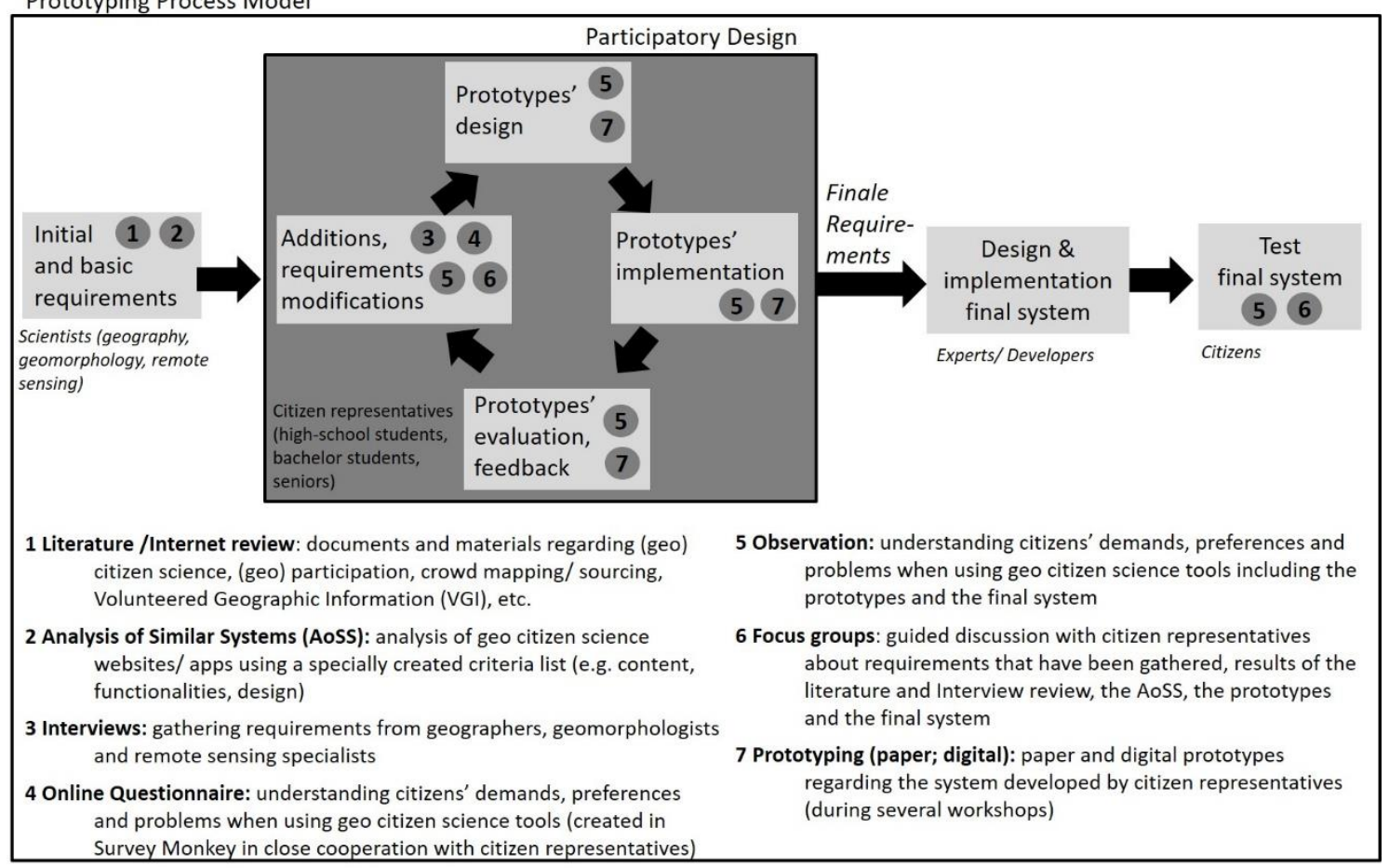

Figure 2: citizenMorph solution development: workflow, approaches, and methods (based on [11]).

To cooperate with citizen representatives in the development process, different methods appropriate to involve laypeople were selected. For the generation of prototypes and the final system Survey123 for ArcGIS, a form-centric solution for creating smart forms/surveys, and the content management system (CMS) WordPress were used. Citizens tested and evaluated the final system on four occasions (mostly taking place in the context of other events). In total, 95 citizens from different backgrounds (e.g., age, gender) were involved in testing to reflect the target group and to provide feedback from different perspectives.

\section{System Requirements, Structure, and Implementation}

Scientists and citizens have several requirements regarding the citizenMorph solution. An overview is given in Figure 3. 

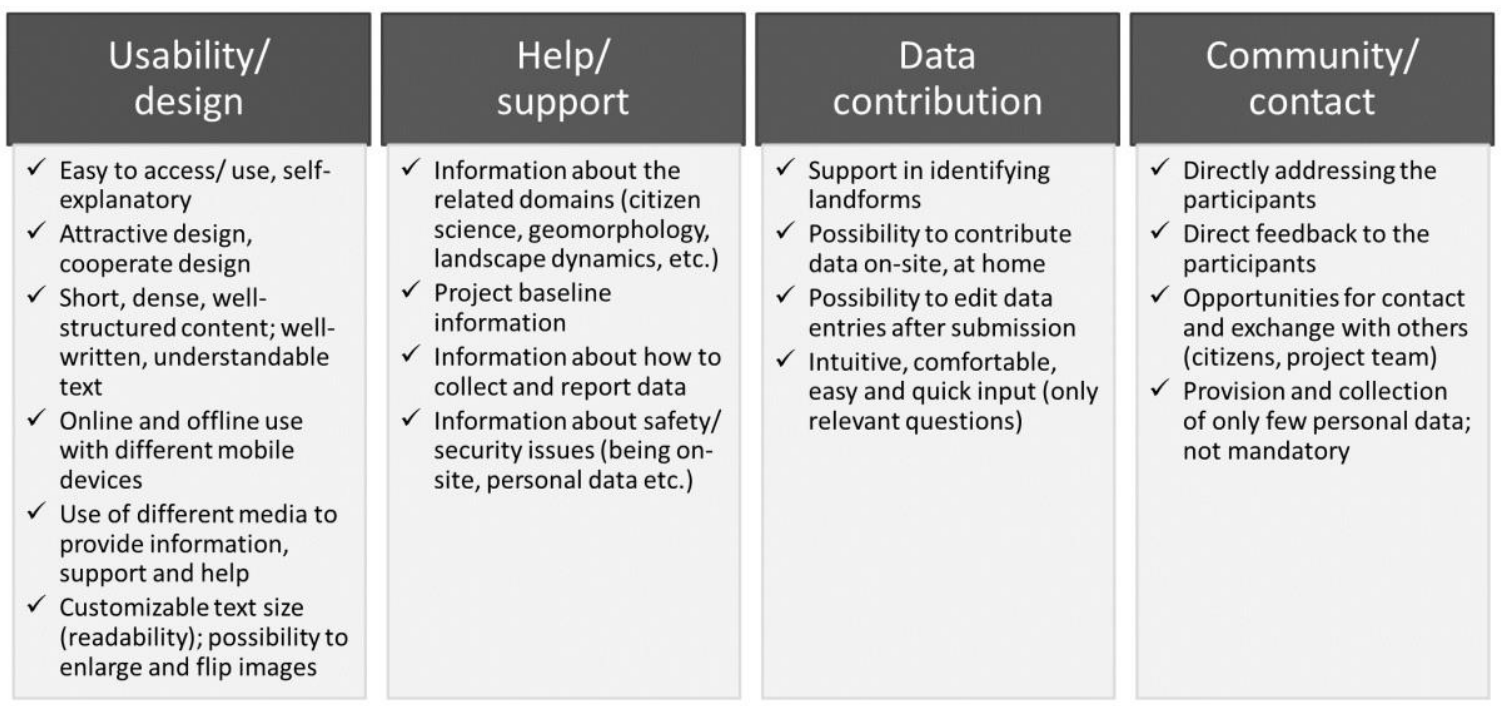

Figure 3: Selection of requirements directed towards the citizenMorph solution.

To meet all requirements, several components are required und were implemented: a data contribution component (smart form/ survey with different types of questions), an extended Internet presence providing comprehensive information about the project and the contribution process, security/ safety and data privacy issues, project progress, and feedback (CMS website), and social webbing opportunities (web 2.0 tools, social networking services). Together, these components, which link to each other and complement each other, build the citizenMorph system (Figure 4).

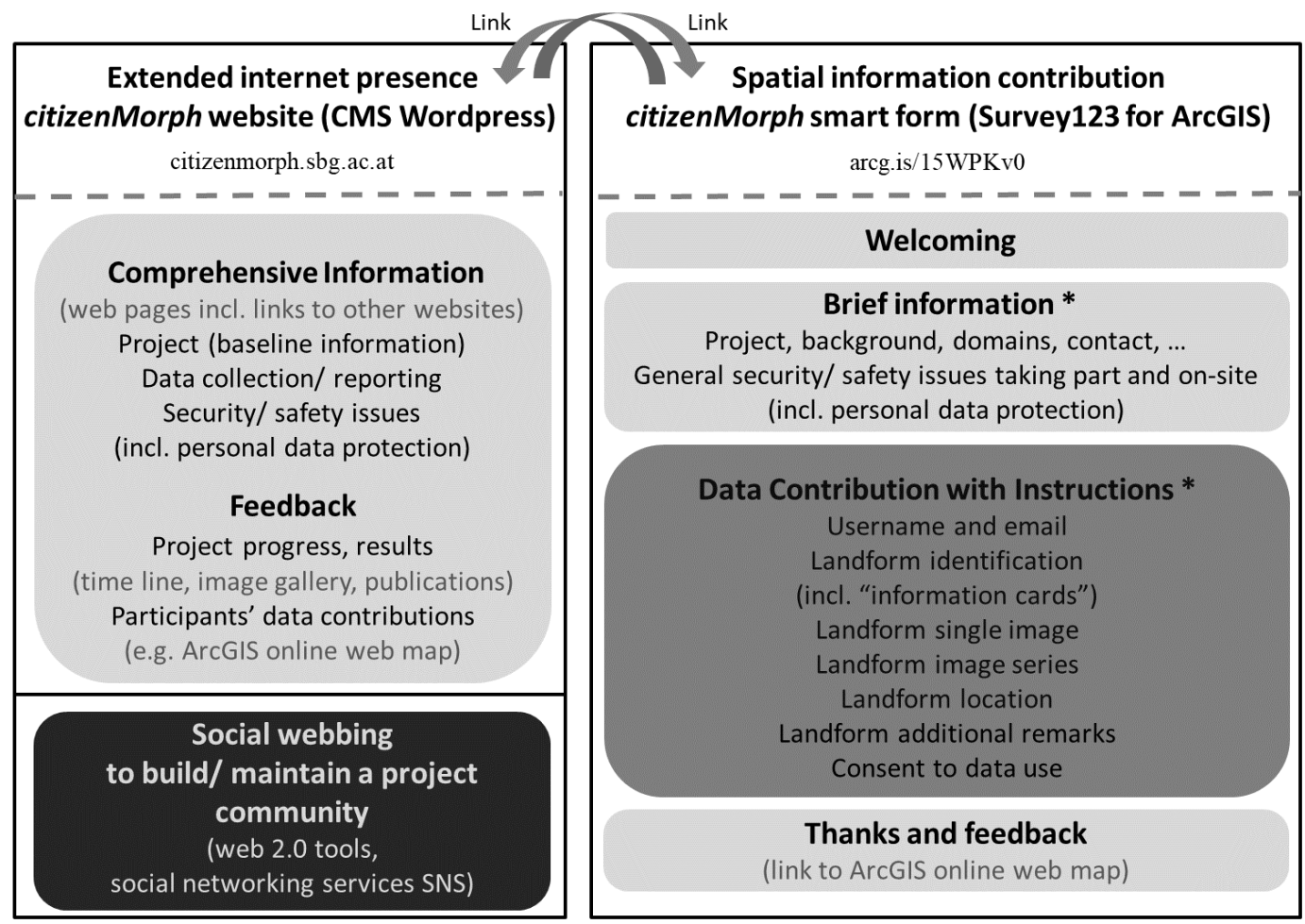

* to read: multiline text, question hint (expand/collapse), links to citizenMorph website; to listen: audio files

Figure 4: citizenMorph system structure with components. 
In addition to the different components, different features and approaches support the citizens, particularly, in the contribution process of landform data:

\section{Level of information}

Information to support and guide citizens in the contribution process is key. Depending on the individual, the need for information varies (newcomers require more information; experienced users less or no information). To face this, in the citizenMorph survey different levels of information are provided (question hints, expandable/ collapsible multiline text; extensive information on the citizenMorph website; Figure 3). The approach of different levels of information brings benefits: descriptions and guidelines will only be presented when desired and needed; volunteers are not demotivated by being overwhelmed with information when getting to know the system and when participating.

\section{Audio files}

Users often refuse to read on-screen. Thus, in addition to text, audio files were created to deliver the most relevant information. This was done by the citizen representatives to prevent delivering too technical content.

\section{Landform identification}

Information cards (jpg images) were created to support the participants in identifying landforms (Figure 2). They present information on the landform type, brief definitions, and explanatory images. To be tailored to the background of the citizens and to increase user experience they were created in cooperation with the citizen representatives.

\section{Community and contact}

No registration and/or login process is needed to contribute data to the citizenMorph project. The optional provision of a username and email allows in-person contact with the participants and to give feedback. This includes delivering an ArcGIS Online web map showing the individual participants' data input.

\section{Conclusion and outlook}

Geomorphology is a complex topic to engage with citizens. To convince and support citizens to participate, technological solutions tailored to their needs are required. To create such a solution, participatory design has been proved to be a useful approach. Cooperating with the citizen representatives revealed the need for a solution that consists of different components: data contribution, information provision, and social webbing. Moreover, additional features and approaches are key: using different media, providing different levels of information and opportunities for contact establishment and community building. However, the results presented refer to initial work; further developments of the system and efforts (subsequent project)are needed to better address and motivate the people for their ongoing engagement in Geomorphology citizen science. 


\section{Acknowledgments}

The Top Citizen Science (TCS) project citizenMorph (FWF-TCS 47), as well as the main project MORPH (FWF-P29461-N29), are funded by the Austrian Science Fund (FWF) and the Austrian Federal Ministry of Transport, Innovation and Technology (BMVIT) under the FFG program "Talente Praktika: Infos für SchülerInnen".

\section{References}

[1] Haklay M. Citizen Science and Volunteered Geographic Information: Overview and Typology of Participation. In: Sui D, Elwood S, Goodchild MF, editors. Crowdsourcing Geogr. Knowl., vol. 9789400745, Dordrecht: Springer Netherlands; 2013, p. 105-22.

[2] Irwin A. No PhDs needed: how citizen science is transforming research. Nature 2018;562:480-2.

[3] Frigerio D, Pipek P, Kimmig S, Winter S, Melzheimer J, Diblíková L, et al. Citizen science and wildlife biology: Synergies and challenges. Ethology 2018;124:365-77.

[4] Cox J, Oh EY, Simmons B, Lintott C, Masters K, Greenhill A, et al. Defining and Measuring Success in Online Citizen Science: A Case Study of Zooniverse Projects. Comput Sci Eng $2015 ; 17: 28-41$.

[5] Liu SB, Poore BS, Snell RJ, Goodman A, Plant NG, Stockdon HF, et al. USGS iCoast-Did the Coast Change? Designing a Crisis Crowdsourcing App to Validate Coastal Change Models. CSCW 2014 • Demonstr., Baltimore, Maryland, USA: 2014, p. 17-20.

[6] Juang CS, Stanley TA, Kirschbaum DB. Using citizen science to expand the global map of landslides: Introducing the Cooperative Open Online Landslide Repository (COOLR). PLoS One 2019; 14:e 0218657.

[7] Simm, D. Boring, boring ... geomorphology? The need for Higher Education to engage with Schools and Further Education. Geophemera, 2008. 102: 6-10.

[8] Baek E-O, Cagiltay K, Boling E, Frick T. User-Centered Design and Development. In: Spector M, Merril D, van Merrienboer J, Driscoll M, editors. Handb. Res. Educ. Commun. Technol. 3rd ed., Abingdon: Routledge; 2007, p. 660-8.

[9] Steen M, Kuijt-Evers L. Early user involvement in research and design projects - A review of methods and practices. 23rd EGOS Colloq., Vienna, Austria: 2007.

[10] Muller MJ, Druin A. Participatory design: The third space in HCI. In: Sears A, Jacko J, Jacko J, editors. Human-Computer Interact. Handb. 2nd ed., Boca Raton: CRC Press; 2007, p. 1087-108.

[11] Hennig S, Hölbling D, Tiede D, Ferber N. Rahmenkonzept und Komponenten für Citizen Science Projekte. Das Projekt citizenMorph. Agit - J Für Angew Geoinformatik, 2019;5:2-13. 